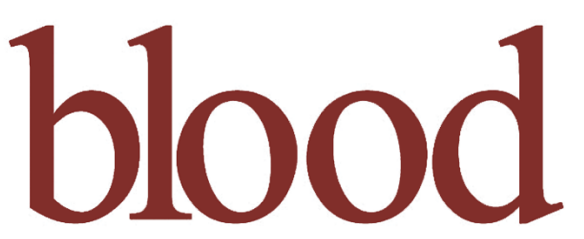

2005 106: 3214-3222

Prepublished online July 28, 2005;

doi:10.1182/blood-2005-05-2013

\title{
Characterization of 8p21.3 chromosomal deletions in B-cell lymphoma: TRAIL-R1 and TRAIL-R2 as candidate dosage-dependent tumor suppressor genes
}

Fanny Rubio-Moscardo, David Blesa, Cinta Mestre, Reiner Siebert, Theo Balasas, Adalberto Benito, Andreas Rosenwald, Joan Climent, Jose I. Martinez, Markus Schilhabel, E. Lorraine Karran, Stefan Gesk, Manel Esteller, Ronald deLeeuw, Louis M. Staudt, Jose Luis Fernandez-Luna, Daniel Pinkel, Martin J. S. Dyer and Jose A. Martinez-Climent

Updated information and services can be found at:

http://bloodjournal.hematologylibrary.org/content/106/9/3214.full.html

Articles on similar topics can be found in the following Blood collections

Neoplasia (4217 articles)

Oncogenes and Tumor Suppressors (795 articles)

Information about reproducing this article in parts or in its entirety may be found online at:

http://bloodjournal.hematologylibrary.org/site/misc/rights.xhtml\#repub_requests

Information about ordering reprints may be found online at:

http://bloodjournal.hematologylibrary.org/site/misc/rights.xhtml\#reprints

Information about subscriptions and ASH membership may be found online at:

http://bloodjournal.hematologylibrary.org/site/subscriptions/index.xhtml

Blood (print ISSN 0006-4971, online ISSN 1528-0020), is published weekly by the American Society of Hematology, 2021 L St, NW, Suite 900,

Washington DC 20036.

Copyright 2011 by The American Society of Hematology; all rights reserved.

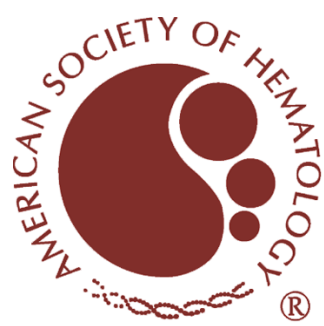




\section{Characterization of 8p21.3 chromosomal deletions in B-cell lymphoma: $T R A I L-R I$ and TRAIL-R2 as candidate dosage-dependent tumor suppressor genes}

Fanny Rubio-Moscardo, David Blesa, Cinta Mestre, Reiner Siebert, Theo Balasas, Adalberto Benito, Andreas Rosenwald, Joan Climent, Jose I. Martinez, Markus Schilhabel, E. Lorraine Karran, Stefan Gesk, Manel Esteller, Ronald deLeeuw, Louis M. Staudt, Jose Luis Fernandez-Luna, Daniel Pinkel, Martin J. S. Dyer, and Jose A. Martinez-Climent

\begin{abstract}
Deletions of chromosome $8 p$ are a recurrent event in B-cell non-Hodgkin lymphoma (B-NHL), suggesting the presence of a tumor suppressor gene. We have characterized these deletions using comparative genomic hybridization to microarrays, fluorescence in situ hybridization (FISH) mapping, DNA sequencing, and functional studies. A minimal deleted region (MDR) of $600 \mathrm{~kb}$ was defined in chromosome 8p21.3, with one mantle cell lymphoma cell line (Z138) exhibiting monoallelic deletion of $650 \mathrm{~kb}$. The MDR extended from bacterial artificial chromosome (BAC) clones RP11-382J24 and
\end{abstract}

RP11-109B10 and included the tumor necrosis factor-related apoptosis-inducing ligand (TRAIL) receptor gene loci. Sequence analysis of the individual expressed genes within the MDR and DNA sequencing of the entire MDR in Z138 did not reveal any mutation. Gene expression analysis and quantitative reverse transcriptase-polymerase chain reaction (QRT-PCR) showed down-regulation of TRAIL-R1 and TRAIL-R2 receptor genes as a consistent event in B-NHL with 8p21.3 loss. Epigenetic inactivation was excluded via promoter methylation analysis. In vitro studies showed that TRAIL- induced apoptosis was dependent on TRAIL-R1 and/or - $R 2$ dosage in most tumors. Resistance to apoptosis of cell lines with 8p21.3 deletion was reversed by restoration of TRAIL-R1 or TRAIL-R2 expression by gene transfection. Our data suggest that TRAIL-R1 and TRAIL-R2 act as dosage-dependent tumor suppressor genes whose monoallelic deletion can impair TRAIL-induced apoptosis in B-cell lymphoma. (Blood. 2005;106:3214-3222)

C 2005 by The American Society of Hematology

\section{Introduction}

B-cell non-Hodgkin lymphomas (B-NHLs) represent a heterogeneous group of disorders characterized in most cases by distinct chromosomal translocations involving the immunoglobulin $(I G)$ genes. ${ }^{1}$ However, these translocations are not sufficient for tumor formation, and other genetic abnormalities including concurrent deregulation of other dominant oncogenes and/or inactivation of tumor suppressor genes (TSGs) are necessary for lymphoma development. 2,3 Physical mapping of chromosome deletions in tumor cells has facilitated the identification of classic TSGs such as $P 16^{I N K 4 a}, A T M, P 53$, and $R B$, by demonstrating mutation of the remaining alleles. ${ }^{4}$ These genes elicit a recessive phenotype and encode proteins that affect several cellular pathways, such as those controlling proliferation, apoptosis, differentiation, and genomic integrity. However, in many other common regions of genomic loss, no TSG carrying biallelic inactivation has been yet identified, indicating that the "2-hit" requirement may not always be necessary for tumorigenesis. Indeed, mutation of a single allele of $P 27$ and P53 is sufficient to promote tumor formation in mice. ${ }^{5,6}$ These haploinsufficient tumor suppressors retain a functional unmutated allele and promote tumorigenesis through reduced gene dosage and subsequently reduced protein levels.

In an initial study using conventional comparative genomic hybridization $(\mathrm{CGH})$ analysis, we reported the presence of a putative tumor suppressor gene locus at the short arm of chromosome 8 (8p) in mantle cell lymphoma. ${ }^{7}$ Subsequent studies have confirmed that this deletion is not only common in mantle cell lymphoma but also in other B-cell malignancies. ${ }^{8-10}$ Chromosome $8 p$ is also one of the most common sites of deletion in epithelial tumors. ${ }^{11-17}$ This genomic loss has been repeatedly associated with tumor progression and advanced or metastatic disease., $, 9,11,17$
From the Center for Applied Medical Research (CIMA), Division of Oncology, University of Navarra, Pamplona, Spain; the Department of Hematology and Medical Oncology, Hospital Clínico, University of Valencia, and the Instituto Investigaciones Citológicas, Valencia, Spain; the Institute of Human Genetics, University Hospital Schleswig-Holstein, Kiel, Germany; the MRC Toxicology Unit, University of Leicester, United Kingdom; the Molecular Genetics Unit, Hospital Universitario Universidad Marqués de Valdecilla, Santander, Spain; the Department of Pathology, University of Würzburg, Germany; the Institute for Molecular Biotechnology, Jena, Germany; the Centro Nacional de Investigaciones Oncológicas (CNIO), Madrid, Spain; the British Columbia Cancer Agency, Vancouver, BC, Canada; the National Cancer Institute, Bethesda, MD; and the Cancer Research Institute, University of California San Francisco, CA.

Submitted May 19, 2005; accepted July 5, 2005. Prepublished online as Blood First Edition Paper, July 28, 2005; DOI 10.1182/blood-2005-05-2013.

Supported by grants from the Spanish Ministries of Health (FIS-01/0015-01) and Science and Technology (SAF-2002/03 173), International Union Against
Cancer (UICC), Spanish Hematology Association (AEHH), FEDER (2000-2006; J.A.M.-C.), UTE-CIMA project (F.R.-M., C.M., J.C., and J.A.M.-C.), European Commission (6FP for Research; J.A.M.-C., R.S., and A.R.), Lymphoma Research Foundation (R.S. and M.J.S.D.), Interdisciplinary Center for Clinical Research (IZKF) Würzburg (A.R.), Instituto de Salud Carlos III/FIS (A.B.), German Human Genome grant 01 KW0002 (M.S.), and the Bud Flanagan Leukemia Fund (T.B. and M.J.S.D.).

The online version of the article contains a data supplement.

Reprints: Jose A. Martinez-Climent, Division of Oncology, Molecular Oncology Lab, Center for Applied Medical Research (CIMA), University of Navarra, Avda Pio XII, 55, Pamplona 31008, Spain; e-mail: jamcliment@unav.es.

The publication costs of this article were defrayed in part by page charge payment. Therefore, and solely to indicate this fact, this article is hereby marked "advertisement" in accordance with 18 U.S.C. section 1734.

C 2005 by The American Society of Hematology 
However, although various potential TSGs have been identified across chromosome 8p, none fulfills the Knudson criteria (presence of biallelic mutation) in a significant portion of tumors. ${ }^{12-16,18,19}$ These findings indicate that this chromosome arm may harbor one or more haploinsufficient tumor suppressor genes. ${ }^{20,21}$

In contrast to carcinomas and sarcomas, a detailed search for a common region of deletion across $8 p$ has not been yet performed in B-NHL. In this report, we delineated a common region of deletion of approximately $600 \mathrm{~kb}$ in $8 \mathrm{p} 21.3$ in various B-NHL subtypes. In vitro assays suggest that TRAIL-R1 and TRAIL-R2 may be the target of the deletion and act as dosage-dependent tumor suppressor genes by impairing the tumor necrosis factor-related apoptosisinducing ligand (TRAIL)-apoptotic pathway.

\section{Material and methods}

\section{Tumor specimens}

To screen for deletions of chromosome 8p, 45 B-cell lymphoma cell lines were studied with genome-wide $\mathrm{CGH}$ to BAC microarrays (array $\mathrm{CGH}$ ): Granta 519, HBL2, SP49, Z138, REC1, NCEB1, JVM2, UPN1, and UPN2 (mantle cell lymphoma); OZ, VAL, Karpas 422, DOHH2, Karpas 353, PR1, OCI-LY8, Karpas 231, SUDHL6, ROS50, RL, SCI1, BEVA, and Granta 452 (diffuse large B-cell lymphoma with $\mathrm{t}(14 ; 18)(\mathrm{q} 32 ; \mathrm{q} 21)$ ); CTB1, MD901, MD903, RIVA, RCK8, and CIPULLO (diffuse large B-cell lymphoma lacking $\mathrm{t}(14 ; 18))$; ELIJAH, NAB2, PL29018, SERAPHINA, Wien133, P32, BALM9, BL41, CA46, Namalwa, and KHM10B (Burkitt lymphoma); SSK41 and Karpas 1718 (marginal zone lymphoma); Karpas 1106 (primary mediastinal B-cell lymphoma); JVM13 (B-cell prolymphocytic leukemia); and GASH (hairy cell leukemia). References for their derivation can be checked in a recently published manuscript. ${ }^{22}$ In addition, lymph node and/or bone marrow samples from 22 patients with B-NHL (9 mantle cell lymphoma, 4 follicle center lymphoma, 4 diffuse large B-cell lymphoma, 3 Burkitt lymphoma, 2 splenic marginal zone lymphoma), and 3 peripheral blood samples from patients with B-cell chronic lymphocytic leukemia (B-CLL), all with suspected 8p deletion as documented by previous cytogenetic or conventional CGH analyses, were also studied. Additional lymph node specimens from 30 patients with B-NHL and 50 peripheral blood or bone marrow samples from patients with B-CLL were studied with fluorescence in situ hybridization (FISH) using the BAC RP11-89M8 that maps to the minimal deleted region (MDR). For mutational analyses, an independent series of 117 lymph node samples from untreated patients with different B-NHL subtypes was also studied. For this study, approval was obtained from the University of Valencia and the University of Navarra institutional review boards. Informed consent was provided according to the Declaration of Helsinki.

\section{Molecular cytogenetic analyses}

Cell lines with chromosome $8 \mathrm{p}$ alterations were studied by G-banding and color cytogenetics using reported methods. ${ }^{7}$ To validate the results of array $\mathrm{CGH}$, cell lines and selected patients with $8 \mathrm{p}$ deletion were analyzed with FISH using 10 bacterial artificial chromosome (BAC) and P1-derived artificial chromosome (PAC) clones mapped across $8 p$ but not included in the array: RP4-605G11 in 8p23.3, CTB-877B12 (8p23.2), GS1-877E9 (8p23.1), GS1-265M2 (8p23.1), GS1-148G17 (8p22), GS1-389E9 (8p21.2), GS1-72M22 (8p21.1), GS1-398G7 (8p12), RP5-826O12 (8p11.22), and GS1-392C11 (8p11.21). Clones were obtained from the Institute for Molecular Biotechnology (Jena, Germany). To delineate the deleted interval further, an additional 15 BAC clones mapped to 8p21 were also studied by FISH in cell lines with the smallest interval of deletion (RP11-110I16, RP11-67H12, RP11-420B22, RP11-233H21, RP11-677P13, RP11-382J24, RP11-582J16, CTD-2238J6, RP11-459E5, RP11-89M8, CTD3188H20, RP11-177H13, RP11-204M16, RP11-288N10, RP11-158F9); these were obtained from the CHORI (Oakland, CA) and from Research Genetics (Invitrogen, Huntsville, AL). The centromere-specific chromo- some 8 probe (CEP 8; Vysis, Downer's Grove, IL) was cohybridized in dual-color FISH experiments. BAC/PAC clones were cultured following standard procedures; DNA was purified and labeled with SpectrumGreendUTP or SpectrumOrange-dUTP (Vysis). FISH results were analyzed using the QUIPS Imaging Software (Vysis) or the ISIS software (MetaSystems, Altlusheim, Germany).

\section{Parallel genomic and gene expression microarray analyses}

An array-CGH microchip with $2460 \mathrm{BAC}$ and P1 clones over the genome (HumArray versions 1.4 and 2.0), which includes 69 clones mapped to chromosome $8 \mathrm{p}$, was applied as reported..$^{23,24}$ After normalization of individual array-CGH experiments, mean $\log _{2}$ ratios (tumoral DNA vs control DNA) were plotted and the resultant graphs were converted to the $\log _{2}$ domain. The observed $\log _{2}$ ratios were excluded from further analysis if there were fewer than 2 replicate spots (out of 3 ) or if the standard deviation of the replicates was above 0.2 . The clones that were present in fewer than $50 \%$ of the samples were also removed from the dataset. Genomic losses were defined when $\log _{2}$ ratios were lower than -0.5 for hemizygosity, and lower than -1.4 for homozygous deletion. To initially investigate the expression of the genes mapped across 8p, the Lymphochip cDNA microarrays were applied to 33 of the B-NHL cell lines, as reported ${ }^{25}$ Chromosome position of cDNA clones was determined according to published genome sequences. Mean expression values for the transcripts mapped across $8 \mathrm{p}$ were compared in deleted versus nondeleted strains, using the Student $t$ test. Values showing $P$ below .05 were then studied using the false discovery rate (FDR) test. An alpha value of less than or equal to 0.01 was considered statistically significant. Supplementary microarray data are provided in Table S1 on the Blood website; see the Supplemental Tables link at the top of the online article.

\section{Submegabase resolution tiling-set (SMRT) array CGH}

To confirm and delineate the borders of the $8 \mathrm{p} 21$ deletions, and to screen for undetected homozygous deletions within the region, 4 primary lymphoma samples with 8p21 deletions and the Z138, JVM2, REC1, SP49, UPN1, G519, HBL2, and NCEB1 cell lines were studied with submegabase resolution tiling-set (SMRT) array CGH, as reported. ${ }^{26}$ This array includes 32433 BACs covering completely the human genome, approximately 500 of which map to chromosome $8 \mathrm{p}$.

\section{Assessment of TRAIL receptor gene expression}

Gene expression of the 4 TRAIL receptor genes, as well as of caspase-8, was determined by reverse transcriptase-polymerase chain reaction (RTPCR). Total RNA was isolated from cell lines using the RNeasy Total RNA Kit (Qiagen, Valencia, CA) according to the manufacturer's protocol. First-strand cDNA synthesis was performed on $1 \mu \mathrm{g}$ total RNA in a volume of $20 \mu \mathrm{L}$ using Superscript II (Life Technologies, Bethesda, MD) and oligo(dT). The specific primers used for mRNA amplification and PCR conditions are shown in Table S2. In addition, quantitative reverse transcriptase-PCR (QRT-PCR) assays for measurement of TRAIL-R1 and TRAIL-R2 mRNA expression was also performed using the primers shown in Table S2. QRT-PCR reactions were performed using the ABIPrism 7700 (PE Applied Biosystems, Foster City, CA) and the SYBr Green I dye. mRNA expression of TRAIL-R1 and TRAIL-R2 was normalized to RNA content for each sample by using glyceraldehyde-3-phosphate dehydrogenase $(\mathrm{GADPH})$ and $\mathrm{TBD}$ gene products as internal controls. The relative expression was calculated as the ratio of expression from each tumor compared with the average expression from the blood mononuclear cells obtained from 12 healthy donors. Cell surface expression of all the TRAIL receptors was evaluated by flow cytometry, using the following monoclonal antibodies: phycoerythrin (PE)-conjugated mouse antihuman TRAIL-R1 (IgG1; clone 69 036); TRAIL-R2 (IgG2b; clone 71 908); TRAIL-R3 (IgG1; clone 90 906); TRAIL-R4 (IgG1; clone 104 918), according to the manufacturer's instructions (R\&D Systems, Minneapolis, MN). The PE-conjugated mouse $\mathrm{IgG} 1, \mathrm{k}$ (clone MOPC-21) or IgG2b, $\mathrm{k}$ (clone 27-35) were used as isotype controls (Becton Dickinson, San Jose, CA). A minimum of 10000 cells was acquired for FACScalibur flow cytometer (BD Biosciences, San 
Jose, CA) and analyzed using Cell Quest software. All experiments were performed at least in duplicate.

\section{Mutation screening and promoter methylation study}

Mutational analysis of genomic DNA from 26 cell lines (12 with 8p21 deletion and 14 without) and 25 B-NHL primary samples (13 with 8p21 deletion and 12 without) was performed by single-strand conformational polymorphism (SSCP) analysis and/or direct sequencing. According to the exon-intron boundary sequences, we designed 35 sets of primers to amplify the entire coding region, including each splicing site, of the TRAIL -R1, TRAIL-R2, TRAIL-R3, and TRAIL-R4 genes, using the Primer 3 program (Table S1). Mutation analysis of the TRAIL-R1 and TRAIL-R2 death domains was performed in the remaining cell lines and in 117 additional patient samples. In addition, $P P P 3 C C$ and $D B C 2$ genes were also sequenced; the complete PPP $3 C C$ cDNA was amplified and direct-sequenced using 3 pairs of primers (Fw1: 5'-TAAGGCTGCCCGAGGAGAAG-3', Rv1: 5'-GGCATCATACACCTGTTCCGA-3', Fw2: 5'-CATGAATGCAGGCATCTTACA-3', Rv2: 5'-TCCATAAAGTTTGGAAGCCAG-3', Fw3: 5'-CCAAGCCACAGGCTTTCCAT-3', Rv3: 5'-TGCACCCTCCAGGTTGAAGTT-3'). For $D C B 2$, the primers used were: E1-4Fw: 5'-CGTGCTCAGCAGGAAGAGATG-3', E1-4Rv: 5'-CAGCCCACCAAGATGACAGG-3', E4-5Fw: 5'-CCCAATTCCCTCCACCATGT3', E4-5Rv: 5'-CAGAGTGGCCCTGGTGGTC-3', E5-6Fw: 5'-TCCACCTCCTCCTCCAAGTTCT-3' E5-6Rv: 5'-CCATCCAGTCACAGCTGGAAA-3', E6-10Fw: 5'-CCAACCGGGTTAAGGAGTGC-3' and E6-10Rv: 5'-GGGTGATGCGGAAGAGCAG- $3^{\prime}$. Mutation status of exons 5 to 9 of $P 53$ gene was also analyzed in selected cell lines; PCR amplification products were purified using a QIAquick PCR Purification Kit (Qiagen) and both DNA strands sequenced by cycle sequencing. Sequence variations were compared with published sequences. A methylation-specific PCR (MSP) method for the analysis of TRAIL-R1, TRAIL-R2, TRAIL-R3, and TRAIL-R4 was applied to the cell lines and primary tumors. Genomic DNA was isolated from cell lines and patient samples using standard procedures. Approximately $1 \mu \mathrm{g}$ DNA was bisulfitemodifed using previously reported methods. ${ }^{27}$ Sequence primers for the MSP analysis of TRAIL-R1, TRAIL-R2, TRAIL-R3, and TRAIL-R4 were designed in the $5^{\prime}$ untranslated region $\mathrm{CpG}$ island of the published sequences near translation start site (Table S2). PCR reactions were hot-started at $95^{\circ} \mathrm{C}$ for 10 minutes, by using $0.25 \mu \mathrm{L}(5 \mathrm{U} / \mu \mathrm{L})$ of Fast Start DNA polymerase (Roche, Barcelona, Spain). Reactions were performed at $58^{\circ} \mathrm{C}$ to $60^{\circ} \mathrm{C}$ annealing temperature. Each PCR reaction was loaded on a $2.5 \%$ agarose gel stained with ethidium bromide and directly visualized under UV illumination. Cp Genome Universal Methylated DNA (Serogicals, Norcross, GA) modified with bisulfite was used as a methylated DNA positive control.

\section{DNA sequencing of $650 \mathrm{~kb}$ spanning the MDR in the $\mathrm{Z} 138$ cell line}

The Z138 cell line was shown to have the shortest interval of loss in 8p21.3. To screen for mutations in the nondeleted allele, a series of primers was designed to amplify the DNA sequence of the $\sim 1 \mathrm{Mb}$ segment between BACs RP11-177H13 (LOXL2 gene) and CTD-2036J7 (PPP3C gene). For resequencing, genomic DNA was amplified by a nested PCR approach. Primers were designed by PRIMER3 (http://fokker.wi.mit.edu/primer3/) using sequences masked by REPEATMASKER. For the first PCR, $100 \mathrm{ng}$ genomic DNA, 10 pmol of each primer, and Taq polymerase (Qiagen, Germany) were used. PCR products were sequenced using primers for the second PCR and Big Dye Terminator Cycle Sequencing kit v3.0 (PE Applied Biosystems). Sequencing reactions were electrophoresed on ABI3700 automated sequencers. Base calling was performed using PHRED, the program for automated sequencer traces. ${ }^{28,29}$ Trace files were assembled, inspected visually, and edited in the GAP4 program. ${ }^{30}$ Sequences were compared with the current UCSC database. Complete sequencing data are provided in Table S3 (http://genome.imb-jena.de/mantle_lymphom/).

\section{TRAIL sensitivity assays}

Cell lines were cultured according to standard conditions. As a positive control, the Jurkat cell line (DSMZ, Braunschweig, Germany), which is sensitive to TRAIL-induced apoptosis, was also included in the study.
Exponentially growing cells were plated at $1 \times 10^{6}$ cells $/ \mathrm{mL}$ of RPMI medium in 24-well microtiter plates. Recombinant human TRAIL (Biomol Research Lab, Plymouth Meeting, MA) at concentrations of 0, 100, 300, and $500 \mathrm{ng} / \mathrm{mL}$ was added. After 24 and 48 hours, apoptotic cells were quantified by staining with fluorescein isothiocyanate (FITC)-conjugated Annexin $\mathrm{V}$ and propidium iodide according to the manufacturer's instructions (BD Pharmingen). Cell fluorescence was detected on a FACScalibur (Becton Dickinson). A minimum of 10000 cells were acquired and analyzed using Cell Quest analysis software. All experiments were performed at least in triplicate.

\section{Transfection assays}

Full-length human TRAIL-R1 and TRAIL-R2 cDNA clones (accession nos. BC012 866 and BC001 281, respectively) were obtained from Invitrogen (ID clone 3857315 human TRAIL-R1 and ID clone 3458466 human TRAIL-R2). Both cDNAs were amplified by PCR with primers listed in Table S2. PCR products were digested with $X b a \mathrm{I}$ and EcoRI (TRAIL-R1) or SpeI and EcoRI (TRAIL-R2) and subcloned into the expression vector pcDNA3-Flag ${ }^{31}$ and sequenced. Namalwa and SUDHL6 cell lines, both carrying the 8p21 deletion, were transfected with $10 \mu \mathrm{g}$ pcDNA3 FlagTRAIL-R1 or pcDNA3 Flag-TRAIL-R2 by electroporation using an Electro Cell Manipulator ECM600 (BTX, Holliston, MA). Transfected cells were selected in the presence of $1 \mathrm{mg} / \mathrm{mL}$ G418 (Invitrogen) containing media, and subsequently maintained with $0.25 \mathrm{mg} / \mathrm{mL}$ to 0.5 $\mathrm{mg} / \mathrm{mL}$ G418. Protein expression of TRAIL-R1 and TRAIL-R2 was analyzed by Western blot and flow cytometry. Apoptosis was determined before and after 24 hours of treatment with TRAIL by staining with FITC-conjugated annexin $\mathrm{V}$ and propidium iodide.

\section{Results}

\section{Delineation of an MDR in 8p21.3 in B-NHL}

To determine the frequency of $8 p$ genomic loss we initially performed BAC array CGH analysis of the B-NHL cell lines and patient samples. Search for genomic losses identified the deletion of chromosome 8p in 12 of 45 (27\%) B-NHL cell lines of different origins (Table 1), and in 20 primary lymphoma samples, corresponding to $18 \mathrm{~B}-\mathrm{NHL}$ (9 mantle cell lymphoma, 3 follicle center lymphoma, 2 diffuse large B-cell lymphoma, 2 Burkitt lymphoma, 2 splenic marginal zone lymphoma) and 2 B-CLL. Comparison of the data from these tumors allowed the delineation of an MDR in 8 p21.3 comprising approximately $1.5 \mathrm{Mb}$ of genomic sequence (Figure 1A). These data were primarily based on the array CGH analysis of 2 cell lines (the MCL-derived Z138 and PR1, derived from a patient with follicle center lymphoma) and patient no. P005 with mantle cell lymphoma, all of which showed interstitial deletions in 8p21 below the resolution of conventional CGH (Figure 1B). Karyotype analysis showed different alterations leading to the loss of chromosome $8 \mathrm{p}$, such as unbalanced translocation, interstitial deletion, or isochromosome formation (Table 1 and Figure 1C). Results of array CGH were independently confirmed by applying FISH with probes mapping to 8p that were not included in the array, but also using clones from the array (Figure 1D). At this level of resolution all deletions were heterozygous.

To delineate the deletion further, BAC/PAC clones covering the $1.5 \mathrm{Mb}$ deleted area were first mapped to cell lines with the smallest deletions using FISH, narrowing the commonly deleted interval down to approximately $0.6 \mathrm{Mb}$. The MDR extended from BACs RP11-382J24 and RP11-109B10 at telomeric and centromeric boundaries, respectively. Notably, one mantle cell lymphoma cell line (Z138) exhibited a monoallelic deletion of 
From bloodjournal.hematologylibrary.org at NAVARRA UNIV on May 11, 2011. For personal use only.

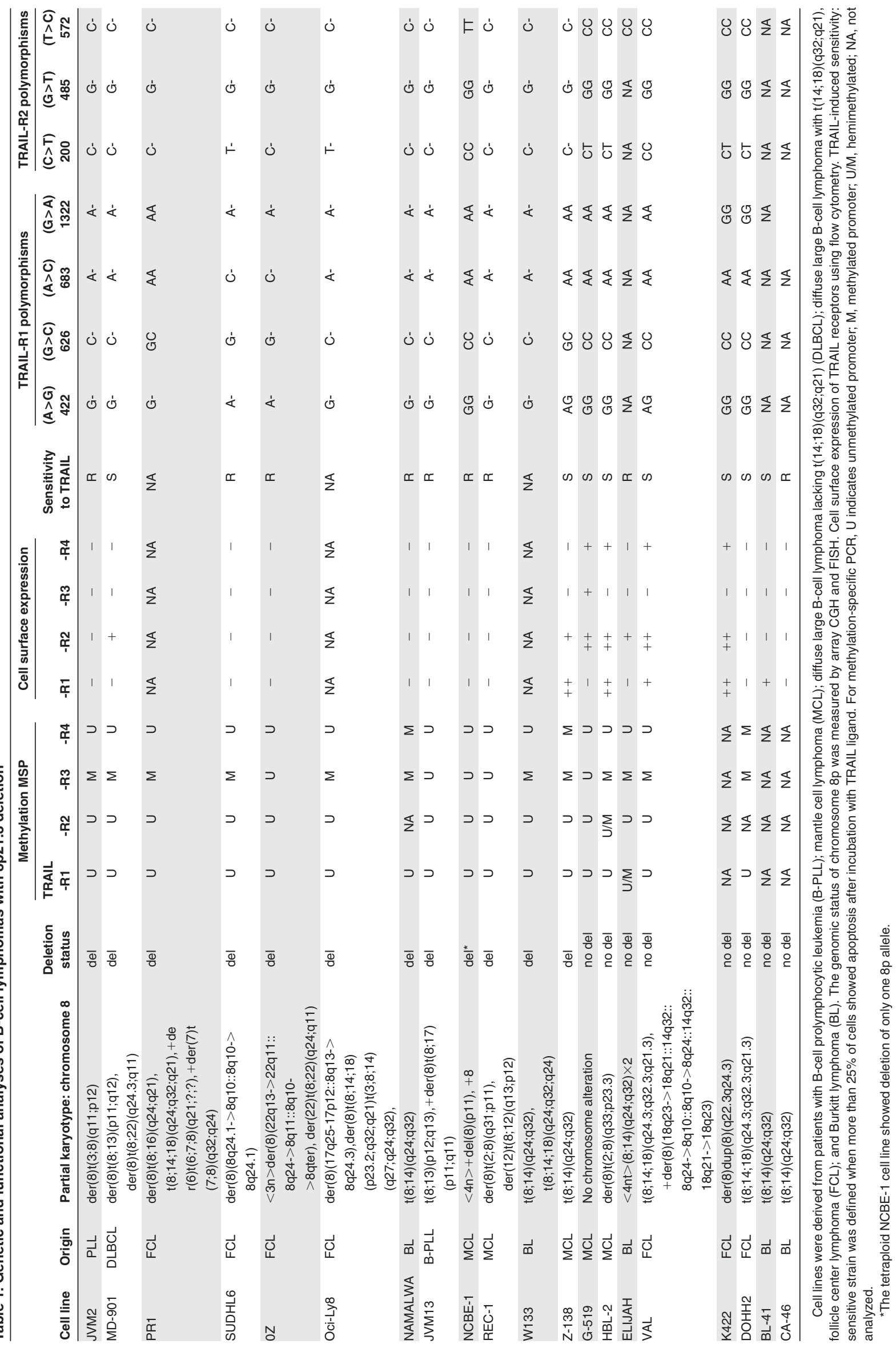


A

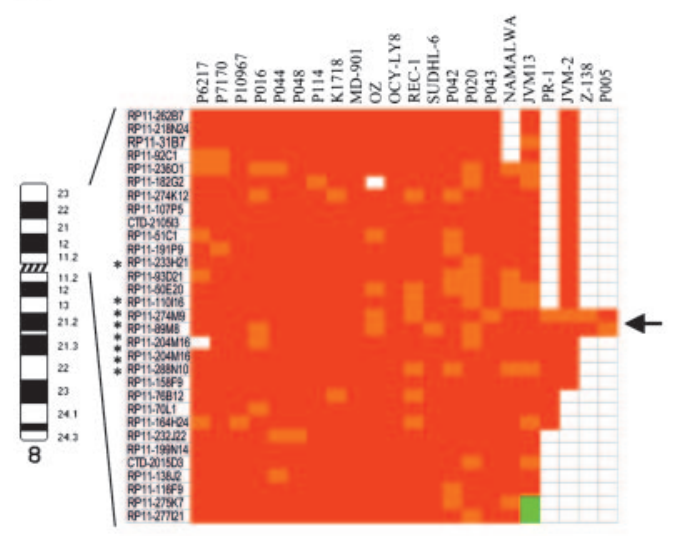

B

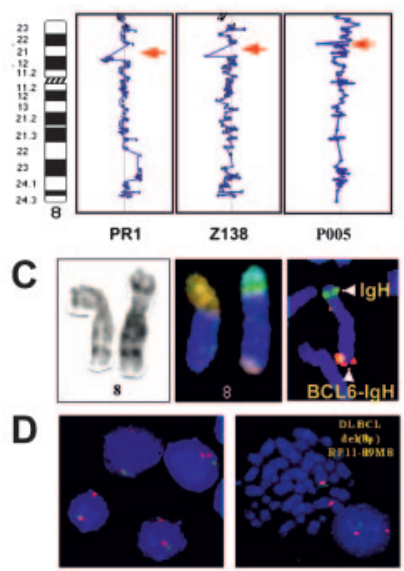

Figure 1. Delineation of a common interval of deletion of $0.6 \mathrm{Mb}$ in 8p21.3 in B-cell lymphomas. (A) Array $\mathrm{CGH}$ analysis shows deleted clones (red), genomic gains (green), nondeleted probes (white), and noninformative clones (orange). Asterisks indicate the clones used for verifying array $\mathrm{CGH}$ results by $\mathrm{FISH}$ analysis in selected cell lines. (B) Array CGH analysis of chromosome 8 in PR1 and Z138 cell lines, and in patient P005, showing genomic deletions in 8 p21 undetected using conventional $\mathrm{CGH}$. (C) G-banding cytogenetic, FISH, and SKY (spectral karyotyping) analyses show deletion of chromosome $8 p$ and translocation of the remaining nondeleted allele in $\mathrm{OCl}$-Ly8 cell line in a complex translocation. (D) FISH analysis of 8p21.3 deletion using BAC RP11-89M8 (green) and a centromeric chromosome 8 probe (red). The examples correspond to 2 patients with transformed splenic marginal zone lymphoma (left) and DLBCL (right). (E) Map of chromosome 8p21.3 including the clones used for narrowing down the commonly deleted interval by array CGH, SMRT array, and FISH (black) (UCSC, May 2004 freeze) ${ }^{53}$ Inset shows the SMRT array CGH analysis of 2 selected cell lines and one primary tumor.

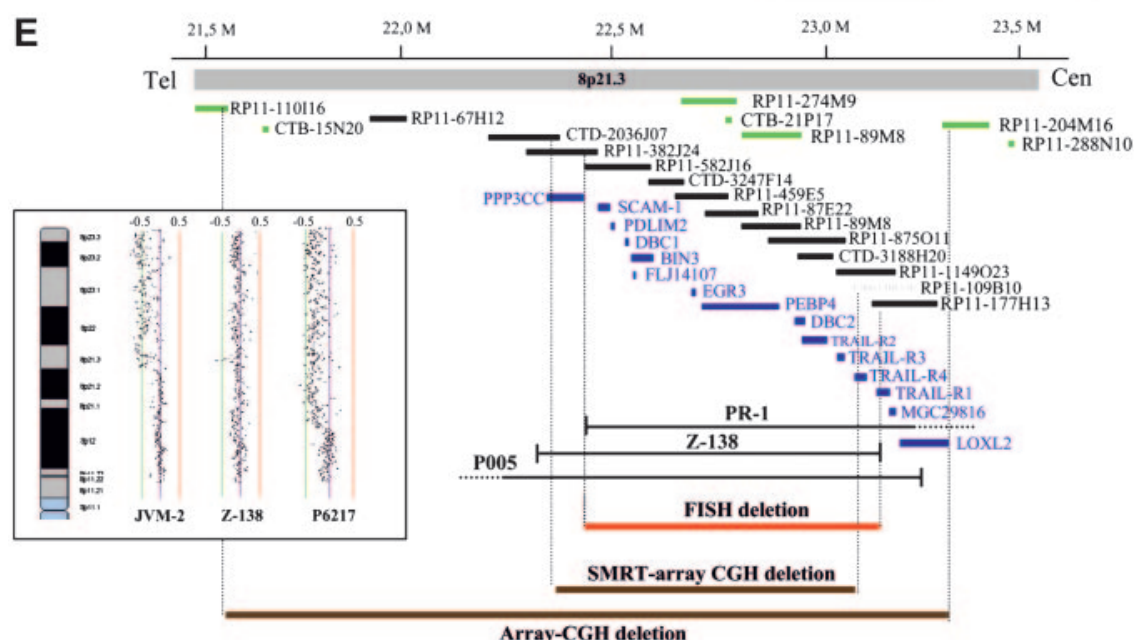

Array-CGH deletion

$650 \mathrm{~kb}$, which included the TRAIL-Rl gene just at the centromeric border. Second, a SMRT array CGH system spanning the entire $8 \mathrm{p}$ arm with approximately 500 BACs was applied to selected cell lines and primary tumors. The SMRT array CGH confirmed 8p21.3 deletions in the 8 tumors with known deletion, including the consensus MDR in all cases, but again, did not detect any homozygous losses. In the Z138 cell line, only 7 of the approximately 500 BACs covering $8 \mathrm{p}$ were deleted, confirming the region of loss of approximately $600 \mathrm{~kb}$ between the TRAIL-RI and PPP3CC genes (Figure 1E). To evaluate further the extent to which the deletion affects B-cell malignancies, we FISHed 80 clinical samples using BAC RP11-89M8. Seven patients showed deletion: 4 with diverse B-NHL subtypes (4 of $30,13 \%)$ and 3 with B-CLL (3 of 50, 6\%).

\section{Mutation analysis of the 8p21.3 MDR in B-NHL}

In the MDR there are 10 known genes, including 3 of the 4 tumor necrosis factor (TNF) receptor superfamily members: the transmembrane proapoptotic death receptor TRAIL-R2 (TNFRSF10A, DR5), and 2 decoy receptors TRAIL-R3 (TNFRSF10C, DCRI) and TRAIL-R4 (TNFRS10D, DcR2). ${ }^{15,32,33}$ Other genes within the MDR were SCAM1, PDLIM2, DBC1, BIN3, EGR3, PEBP4, and RHOBTB2/DBC2. Notably, the TRAIL-R1 gene (TNFRSF10A, $D R 4$ ) was just at the centromeric border of the deletion in the Z138 cell line, but it was shown to be deleted in all the remaining 31 lymphomas with 8p21.3 deletion. At the telomeric border of the deletion, the PPP3C gene was not included in the MDR based on the data from the PR1 cell line (Figure 1E). Next we sought potentially pathogenic mutations in the genes within the MDR. Given the functions of the TRAIL receptor genes in signaling apoptosis, we focused on these genes initially. The complete coding regions plus splicing intron-exon sites of the 4 TRAIL-receptor genes were sequenced in 26 cell lines and 25 primary samples. In addition, because mutations in the death domain of TRAIL-RI and $T R A I L-R 2$ have been reported at low frequency in human tumors ${ }^{34,35}$ both death domains were sequenced in an additional 117 B-NHL biopsies. No mutation was detected in tumors with and without $8 \mathrm{p}$ deletions, although known and several novel polymorphisms were observed (Table S4). Mutations were also excluded in 2 putative TSGs mapped to $8 \mathrm{p} 21$, deleted in breast cancer 2 $(D B C 2)$ and $P P P 3 C C$. In these, several polymorphisms were identified, which are shown in Supplemental Table D. In addition, the interval of genomic loss in 8p21.3 in the Z138 cell line, consisting of $650 \mathrm{~kb}$ of genomic DNA, which was the shortest deletion ranging from BAC RP11-177H13 to BAC CTD-2036J07, was completely sequenced. No unexpected changes other than common polymorphisms in the genes within the MDR were found (Table S3).

\section{Hemizygous loss of TRAIL receptor genes results in down-regulation of cell surface expression of TRAIL receptor proteins}

To determine whether chromosome $8 \mathrm{p}$ deletion affected gene expression across the genomic region at $8 \mathrm{p}$, we assessed gene 
expression using the Lymphochip cDNA microarray. Among 79 genes/ESTs that mapped to $8 \mathrm{p}$ in the Lymphochip microarray, only $5(6 \%)$ showed statistically significant down-regulation in cell lines with $8 \mathrm{p}$ loss with respect to those with both alleles intact (Figure 2A). Notably, only 2 of these down-regulated cDNAs mapped into the critical region at $8 \mathrm{p} 21.3$, and both corresponded to TRAIL-R2. The other cDNAs corresponded to HSPCO35 at 8p12, PPP3CC at 8p21, and FBXO25 at 8p23.3. TRAIL-R1 is not included in the Lymphochip microarray. RT-PCR analysis showed that TRAIL-R1 and TRAIL-R2 were expressed in all cell lines, whereas expression of TRAIL-R3 was absent in 12 of $12(100 \%)$ samples with 8 p deletion and in 7 of 8 ( $87 \%)$ of nondeleted specimens. TRAIL-R4 was also expressed in all tumors (20 of 20,100\%), and expression of caspase- 8 was present in all cell lines (Figure 2B). QRT-PCR indicated decreased expression levels of TRAIL-R1 and TRAIL-R2 in cell lines carrying deletion of $8 \mathrm{p} 21.3(P<.01)$. Measurement of cell surface expression of TRAIL receptors using flow cytometry showed that both TRAIL-R1 and TRAIL-R2 were underexpressed in deleted cell lines, whereas TRAIL-R3 and TRAIL-R4 were similarly expressed both in deleted and nondeleted cell lines (Figure 2C). Because promoter methylation may be responsible for down-regulation of the TRAIL receptor genes in cancer, ${ }^{36}$ we studied the methylation pattern of these genes in cell lines and primary tumors. Methylation of TRAIL-RI and TRAIL-R2 was not observed in 26 tumors carrying deletion of $8 \mathrm{p}$, but was observed in 5 and 7 of 38 nondeleted cell lines and biopsy samples (13\% and $18 \%$, respectively). Methylation of TRAIL-R3 was identified in 12 of 20 tumors (60\%) with $8 \mathrm{p}$ deletions, but also in 22 of 38 nondeleted samples (55\%), indicating a good correlation with expression data in most tumors. On the contrary, TRAIL-R4 was rarely methylated, and only in nondeleted tumor cells (Figure 2D).

\section{Sensitivity to TRAIL-induced apoptosis is dependent on TRAIL-R1 and TRAIL-R2 gene and protein dosage}

Regulation and maintenance of expression of death and decoy receptors is critical for controlling apoptosis. ${ }^{33,37,38}$ Examination of TRAIL-induced apoptotic response in the lymphoma cell lines after exposure to different TRAIL doses revealed that TRAILmediated apoptosis was directly related to TRAIL-R1 and TRAIL-R2 expression in most tumors, but not to that of TRAIL-R3/TRAIL-R4 (Figure 3A). Resistance to apoptosis was higher in cell lines with 8 p deletion versus nondeleted strains: 7 (78\%) of 9 versus $2(25 \%)$ of 8 of tumors showed less than $25 \%$ cell apoptosis after a 24 -hour incubation with $500 \mathrm{ng}$ TRAIL, respectively. The Z138 cell line, which exhibits deletion of TRAIL-R2 and showed TRAIL-R1 to be mapped at the centromeric border of the deletion in $8 \mathrm{p} 21.3$, was sensitive to TRAIL-induced apoptosis; expression levels of the receptors were higher for TRAIL-R1 than for TRAIL-R2, suggesting that in Z138 cells the TRAIL-induced sensitivity may be mediated via TRAIL-R1 signaling. In the MD901 cell line, which shows deletion of both TRAIL-R1 and TRAIL-R2 genes and is sensitive to TRAIL-induced apoptosis, expression of TRAIL-R1 was very low but TRAIL-R2 was expressed at higher levels, perhaps indicating signaling through TRAIL-R2 receptor. Because polymorphisms in the untranslated regions of TRAIL receptor genes have been involved in the translational control of TRAIL-R2 expression in melanoma cells, ${ }^{39}$ we checked whether a $3^{\prime} \mathrm{UTR}$ region of TRAIL-R2 as well as other known and novel polymorphisms observed in the TRAIL receptors correlated with the levels
A

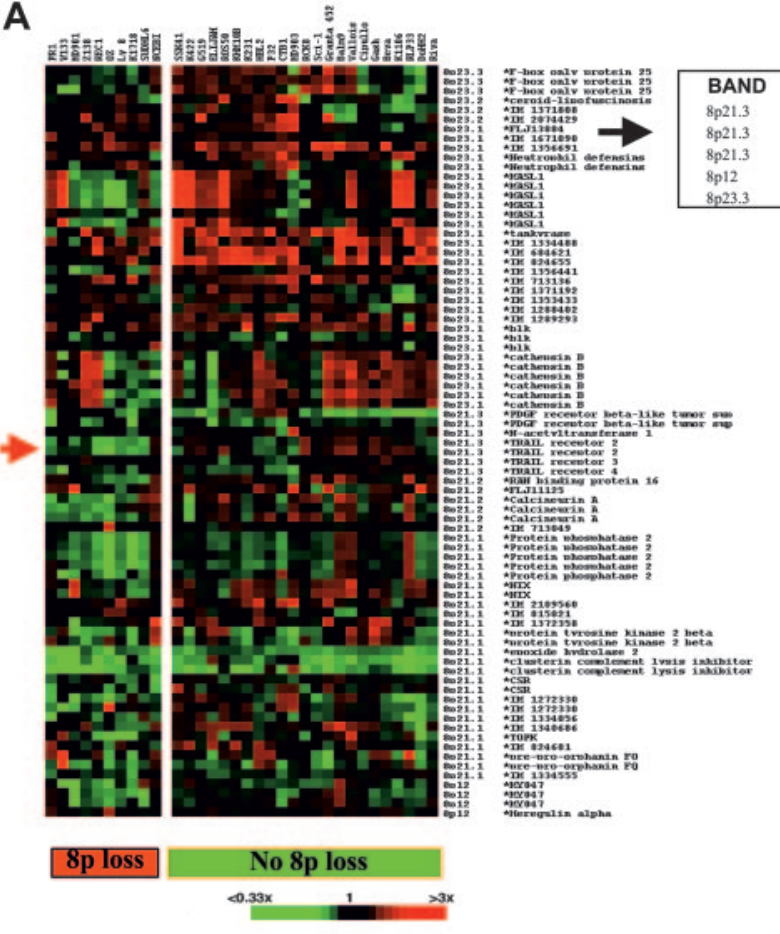

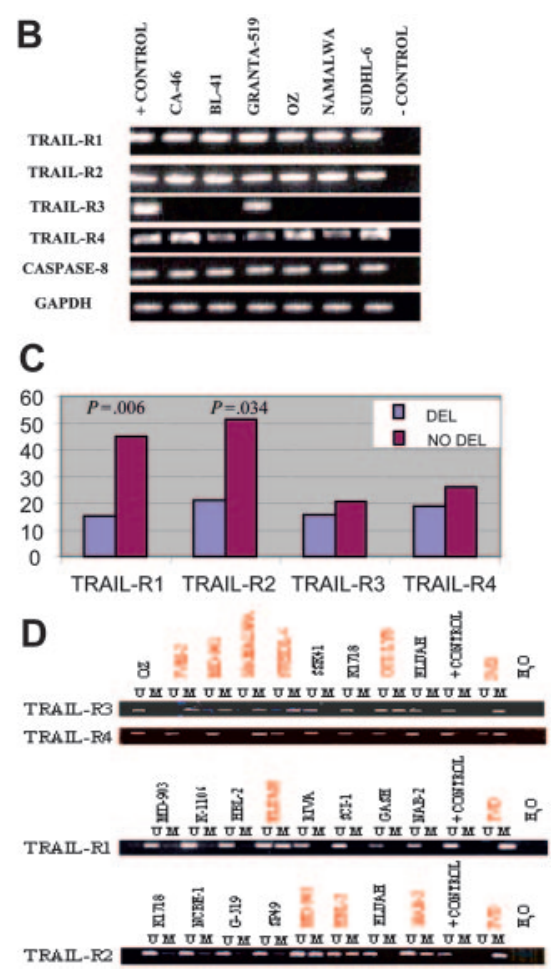

Figure 2. Gene expression analysis of tumors with 8p deletion. (A) Representation of gene expression analysis of cell lines with deletion of $8 p$ (left) and those without genomic deletion (right). Array indicates the position of TRAIL receptor genes in the array. The 5 clones with statistically significant decreased expression in cell lines with deletion versus nondeleted strains are shown. (B) RT-PCR analysis for TRAIL receptor genes and the caspase 8 gene. (C) Flow cytometry analysis for TRAIL receptor genes showed reduced expression for TRAIL-R1 and TRAIL-R2 in deleted versus nondeleted cell lines and patient samples. (D) Methylation analysis: representative examples of cell line samples. U indicates unmethylated; M, methylated; IVD, methylated positive control. In red, cell lines showing methylation of the corresponding gene. 
A SUDHL-6
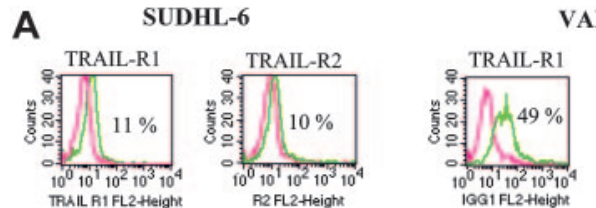

VAL

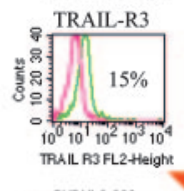

TRAIL-R4

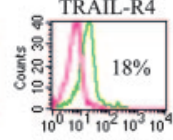

$10^{-10} 10^{2} 10^{3} 10^{4}$
TRALL RAFL2 Height
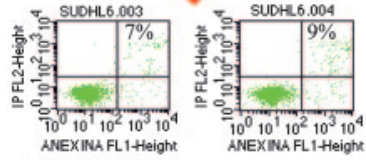

CONTROL 24H TRAIL $500 \mathrm{ng} / \mathrm{mL} 24 \mathrm{H}$

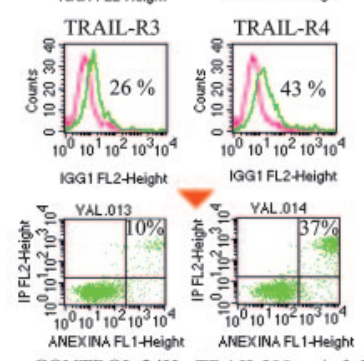

CONTROL 24H TRAIL500 ng/mL 24H

B
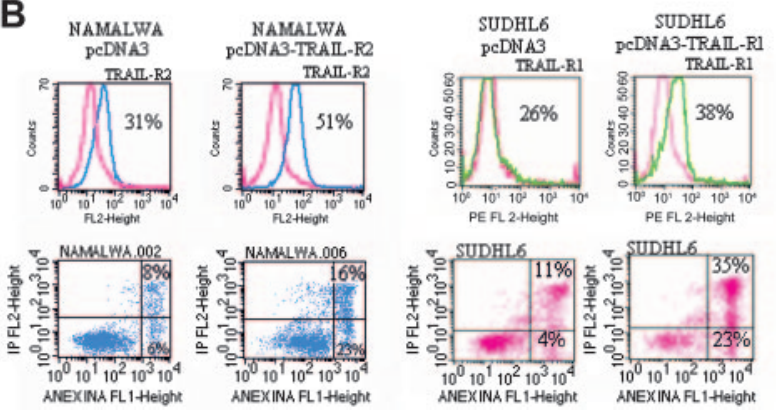

Figure 3 . In vitro and in vivo assays implicating TRAIL-R2 as a candidate dosage-dependent tumor suppressor in B-cell lymphoma. (A) TRAIL-induced apoptosis response in SU-DHL6 (resistant to TRAIL-induced apoptosis) and VAL (sensitive to TRAIL-induced apoptosis) cell lines. Cell surface expression of the 4 TRAIL receptors was determined by flow cytometry. Fresh SUDHL6 and VAL cells were incubated in the presence of recombinant human TRAIL $(500 \mathrm{ng} / \mathrm{mL})$. After 24 hours, cell death was quantified by flow cytometric analysis after staining with FITC-conjugated Annexin V and propidium iodide; the percentage of dead cells is indicated. (B) Namalwa and SUDHL6 cell lines, both carrying 8p21 deletion, were transfected with pcDNA3 Flag-TRAIL-R1 or pcDNA3 Flag-TRAIL-R2. Transfected cells were selected in the presence of G418-containing media, and subsequently maintained with $0.25 \mathrm{mg} / \mathrm{mL}$ to $0.5 \mathrm{mg} / \mathrm{mL} \mathrm{G} 418$. Protein expression TRAIL-R1 and TRAIL-R2 were analyzed by Western blot and flow cytometry. Flow cytometry analysis of cell surface expression of TRAIL-R1 and TRAIL-R2 receptors after cell transfection in SU-DHL6 and Namalwa is shown. Apoptosis was determined before and after 24 hours of treatment with TRAIL. Restoration of expression levels of TRAIL-R1 and TRAIL-R2 by less than 2-fold was associated with increased TRAIL-induced apoptosis, as shown by the percentage of apoptotic cells in the cell lines transfected with the empty vector compared with those transfected with pcDNA-TRAIL-R1 and R2.

of expression of the receptors and/or the resistance to TRAILinduced apoptosis. None of the polymorphisms was associated with differences in expression or sensitivity to TRAIL-induced apoptosis (Table 1). To investigate whether the P53 gene, which directly binds to the TRAIL-R2 promoter and signals apoptotic death ${ }^{40}$ carried mutations that may have influenced in the TRAIL sensitivity, we screened for P53 mutations. Inactivating mutations were observed in one of the sensitive cell lines (MD901) but also in resistant strains (Namalwa), excluding correlation with TRAIL-RI/ TRAIL-R2 expression or with TRAIL-mediated apoptosis.

\section{Restoration of TRAIL-R1 and TRAIL-R2 expression reversed resistance to TRAIL-mediated apoptosis}

In search for a model, we evaluated whether variation in TRAIL-R1 and/or TRAIL-R2 expression levels after gene transfection enhanced TRAIL-induced apoptosis in B-cells. FLAG-tagged $T R A I L-R 1$ and TRAIL-R2 expression constructs were transfected alone and cotransfected simultaneously into 5 lymphoma cell lines with 8 p loss (Namalwa, SUDHL6, REC1, JVM2, and NCEB1). We only obtained stable transfections of TRAIL-R2 in Namalwa cells, derived from Burkitt lymphoma, and of TRAIL-R1 in the SUDHL6 cell line, derived from diffuse large B-cell lymphoma with $\mathrm{t}(14 ; 18)(\mathrm{q} 32 ; \mathrm{q} 21)$. Both cell lines showed deletion of $8 \mathrm{p} 21.3$, including TRAIL-R1 and TRAIL-R2 gene loci, and were resistant to TRAIL-induced apoptosis. In both, expression of TRAIL-R1 and $\mathrm{R} 2$ was increased by less than 2-fold, resembling the expression levels of most cell lines with 2 8p21.3 alleles. Increased TRAIL-R2 expression in Namalwa cells and TRAIL-R1 expression in SUDHL6 were both associated with restoration of TRAIL-induced sensitivity, whereas nontransfected cell lines used as controls remained resistant (Figure 3B). These data indicated that the extrinsic apoptotic pathway was not structurally damaged in these 2 cell lines and that TRAIL-induced apoptosis was reversible with expression of the receptors, depending on TRAIL-R1 and TRAIL-R2 protein dosage. Therefore, TRAIL-R1 and TRAIL-R2 seem to show a gene-dosage effect that can be disrupted by chromosome deletion, thus impairing TRAIL-induced apoptosis in B cells.

\section{Discussion}

Genetic analysis has suggested that deletion of sequences that map to chromosome $8 \mathrm{p}$ may be critical for tumorigenesis in epithelial carcinomas as well as in hematologic malignancies. ${ }^{21}$ However, a marked heterogeneity in the different publications has led to the description of several critical regions of deletion in $8 \mathrm{p}$. Here, we delineate an MDR in chromosome 8p21.3 that is coincident with some of the reported deletions in other tumors. Among the previous reports, Hamaguchi et $\mathrm{al}^{15}$ used representational difference analysis to narrow down a region of homozygous deletion in breast cancer overlapping with ours that contained TRAIL-R2 but not TRAIL-R1, whereas Swalwell et $\mathrm{al}^{41}$ analyzed microsatellite markers for loss of heterozygosity $(\mathrm{LOH})$ in prostate tumors and delineated an MDR of $1.5 \mathrm{Mb}$ in $8 \mathrm{p} 21.3$ including the 4 TRAIL receptor genes. In 2 additional publications using microsatellite analysis, common regions of deletions spanning $8 \mathrm{p} 21.3$ were identified in non-small lung and colorectal carcinomas. ${ }^{42,43}$ With the combination of high-resolution array $\mathrm{CGH}$ and FISH mapping, we defined the MDR to $600 \mathrm{~kb}$ in $8 \mathrm{p} 21.3$ that may harbor one or more tumor suppressor genes involved not only in B-cell lymphoma, but also in other cancer types.

Monoallelic deletion with concurrent mutation of the remaining allele and/or promoter methylation is a common mechanism of inactivation for tumor suppressor genes. Among the genes located within the MDR, the TRAIL receptor genes were selected initially based on their roles in signaling apoptosis and because mutations of TRAIL-R1 and TRAIL-R2 had been reported in lymphoma and in other cancers. ${ }^{34,35}$ However, we failed to identify any pathogenic mutation or promoter methylation in TRAIL-R1 and TRAIL-R2. In addition, obvious pathogenic mutations were excluded in the candidate tumor suppressor $D B C 2$, contained within the MDR, and in the PPP3C gene, located at the telomeric border of the MRD. Sequencing of the entire interval of MDR in the Z138 cell line failed to identify sequence changes in all the genes within the MDR as well. Notably, the gene encoding the decoy receptor TRAIL-R3 showed frequent hemizygous loss plus silencing of the second allele by promoter methylation, therefore fulfilling the criteria for "2-hit" TSGs. However, this decoy receptor does not contain a functional domain, and seems to block TRAIL-induced apoptosis by competing with TRAIL-R1 and TRAIL-R2. ${ }^{33,37}$ Therefore, this 
gene may not be considered a tumor suppressor gene a priori, but we cannot exclude that TRAIL-R3 could have unreported functions besides its role as decoy receptor and might be implicated in the lymphoma pathogenesis. It should be noted that within the MDR described here there are no identified micro-RNA genes.

In the absence of any pathogenic mutations there is currently no conclusive proof of which, if any, of the genes studied represent true oncogenic targets. To explain the apparent lack of a conventional tumor suppressor gene in $8 \mathrm{p}$, gene inactivation through alternative mechanisms such as haploinsufficiency were postulated. Our data suggest that deletion-induced haploinsufficiency of TRAIL-R1/R2 can impair TRAIL-induced apoptosis and thus contribute to tumorigenesis in B cells through a gene dosage effect. Indeed, in our system model, overexpression of TRAIL-R1 and-R2 was massive but only by less than 2-fold, mimicking the difference between haploinsufficiency and wild-type tumors without $8 \mathrm{p} 21.3$ deletions. In agreement with our results, Chaib et $\mathrm{al}^{20}$ reported that haploinsufficiency and transcriptional down-regulation for genes mapping to $8 \mathrm{p}$, including $T R A I L-R 1 / R 2$, are coincident in human prostate tumors. Also in agreement with these data, several reports indicate that TRAIL can induce rejection or apoptosis of tumor cells. ${ }^{44-48}$ Cretney et $\mathrm{al}^{48}$ reported that TRAIL knock-out mice were more susceptible to experimental and spontaneous tumor metastasis, whereas Takeda et $\mathrm{al}^{46}$ found that development of spontaneous tumors in $\mathrm{p} 53^{+/-}$mice was promoted by neutralization of TRAIL. However, the role of the TRAIL receptors' deficiency in suppressing tumorigenesis in vivo has been investigated only recently. Diehl et $\mathrm{l}^{49}$ reported the generation of TRAIL receptor (TRAIL-R)deficient mice (mDR5, mTRAILR2, or mKILLER), the only full-length TRAIL receptor in mouse with equal homology to human TRAIL-RI and TRAIL-R2. Mice were born at the expected Mendelian ratios and showed no developmental abnormalities. The authors defined a role for TRAIL-R signaling independent of its ability to initiate apoptosis in sensitive cells. Remarkably, these animals did not develop tumors spontaneously. More importantly, crossing of the TRAIL-R-deficient mice with $p 53^{-1-}$ mice and with $A p c^{M I N /+}$ mice, 2 well-established models of tumorigenesis, did not affect the onset or growth of T-cell thymomas and intestinal tumors, respectively. ${ }^{50}$ The role of TRAIL-R deficiency was not evaluated, however, in a B-cell lymphoma mouse model, and thus cannot be fully compared with our results. Finnberg et al ${ }^{51}$ created another knock-out mouse lacking TRAIL-R. This mouse was viable and developed normally with the exception of enlarged thymus. Authors showed that loss of TRAIL-R diminished apoptosis in immortalized cells. In addition, they showed that TRAIL-R plays a role in the DNA damage response of the immune cells of the thymus and of the spleen and in particular in the lymphocytes of the white pulp. These data may help to interpret our results, as we can hypothesize that TRAIL-R1 and -R2 show different function in B-cell lymphocytes, including modulation of TRAIL-induced apoptosis. Consequently, TRAIL-R1 and/or TRAIL-R2 might show tumor suppressor activity in B-cell lymphoma, as we have initially shown in this manuscript. We may also speculate on different roles of TRAIL receptors in humans compared with mice, which only bear one TRAIL receptor instead of the 2 observed in humans and primates. ${ }^{52}$ Further experimental studies will clarify whether TRAIL-R deficiency may enhance tumor formation in wellcharacterized B-cell lymphoma mouse models.

In summary, we have delineated a novel MDR in chromosome $8 \mathrm{p} 21.3$ and have provided data that suggest that TRAIL-RI and $T R A I L-R 2$ genes are the targets of the deletion. These genes may act as dosage-dependent suppressor genes by impairing the TRAILapoptotic pathway in B-cell lymphoma.

\section{Acknowledgments}

We thank Dr I. Marugan for providing patient material and M. Marin for QRT-PCR analysis (Valencia, Spain); Dr A. Karpas (Cambridge, United Kingdom) and A. Turhan (Paris, France) for providing Karpas 1718 and UPN1/2 cell lines, respectively; Drs F. Solé (Barcelona, Spain), J.C. Cigudosa (Madrid, Spain), and M.D. Odero (Pamplona, Spain) for assistance with color cytogenetic analysis; Dr J.F. García (Madrid, Spain) for pathologic review; and Professor I. Melero (Pamplona, Spain) for critical review of the manuscript.

\section{References}

1. Harris NL, Jaffe ES, Diebold J, et al. The World Health Organization classification of neoplasms of the hematopoietic and lymphoid tissues: report of the Clinical Advisory Committee meeting-Airlie House, Virginia, November, 1997. Hematol J. 2000;1:53-66.

2. McDonnell TJ, Korsmeyer SJ. Progression from lymphoid hyperplasia to high-grade malignant lymphoma in mice transgenic for the $t(14 ; 18)$. Nature. 1991;349:254-256.

3. Lovec H, Grzeschiczek A, Kowalski MB, Moroy T. Cyclin D1/bcl-1 cooperates with myc genes in the generation of B-cell lymphoma in transgenic mice. Embo J. 1994;13:3487-3495.

4. Knudson AG. Two genetic hits (more or less) to cancer. Nat Rev Cancer. 2001;1:157-162.

5. Fero ML, Randel E, Gurley KE, Roberts JM, Kemp CJ. The murine gene p27Kip1 is haploinsufficient for tumour suppression. Nature. 1998; 396:177-180.

6. Venkatachalam S, Shi YP, Jones SN, et al. Retention of wild-type p53 in tumors from p53 heterozygous mice: reduction of $p 53$ dosage can promote cancer formation. Embo J. 1998;17: 4657-4667.

7. Martinez-Climent JA, Vizcarra E, Sanchez D, et al. Loss of a novel tumor suppressor gene locus at chromosome $8 p$ is associated with leukemic mantle cell lymphoma. Blood. 2001;98:34793482.

8. Berglund M, Enblad G, Flordal E, et al. Chromosomal imbalances in diffuse large B-cell lymphoma detected by comparative genomic hybridization. Mod Pathol. 2002;15:807-816.

9. Bea S, Lopez-Guillermo A, Ribas M, et al. Genetic imbalances in progressed B-cell chronic lymphocytic leukemia and transformed large-cell lymphoma (Richter's syndrome). Am J Pathol. 2002;161:957-968.

10. Kohlhammer $\mathrm{H}$, Schwaenen $\mathrm{C}$, Wessendorf $\mathrm{S}$, et al. Genomic DNA-chip hybridization in $\mathrm{t}(11 ; 14)$ positive mantle cell lymphomas shows a high frequency of aberrations and allows a refined characterization of consensus regions. Blood. 2004; 104:795-801.

11. Qin LX, Tang ZY, Sham JS, et al. The association of chromosome $8 p$ deletion and tumor metastasis in human hepatocellular carcinoma. Cancer Res. 1999;59:5662-5665.

12. Fujiwara $\mathrm{Y}$, Ohata $\mathrm{H}$, Kuroki $\mathrm{T}$, et al. Isolation of a candidate tumor suppressor gene on chromosome 8p21.3-p22 that is homologous to an extracellular domain of the PDGF receptor beta gene. Oncogene. 1995;10:891-895.
13. Hubbard AL, Harrison DJ, Moyes C, et al. Nacetyltransferase 2 genotype in colorectal cancer and selective gene retention in cancers with chromosome 8p deletions. Gut. 1997;41:229234.

14. Ishii H, Baffa R, Numata SI, et al. The FEZ1 gene at chromosome 8p22 encodes a leucine-zipper protein, and its expression is altered in multiple human tumors. Proc Natl Acad Sci U S A. 1999; 96:3928-3933.

15. Hamaguchi M, Meth JL, von Klitzing C, et al. DBC2, a candidate for a tumor suppressor gene involved in breast cancer. Proc Natl Acad Sci U S A. 2002;99:13647-13652.

16. Kim TY, Jong HS, Song SH, et al. Transcriptional silencing of the DLC-1 tumor suppressor gene by epigenetic mechanism in gastric cancer cells. Oncogene. 2003;22:3943-3951.

17. Yokota T, Yoshimoto M, Akiyama F, et al. Localization of a tumor suppressor gene associated with the progression of human breast carcinoma within a 1-cM interval of 8p22-p23.1. Cancer. 1999;85:447-452.

18. MacGrogan D, Levy A, Bova GS, Isaacs WB, Bookstein R. Structure and methylation-associated silencing of a gene within a homozygously 
deleted region of human chromosome band 8p22. Genomics. 1996;35:55-65.

19. Lai J, Flanagan J, Phillips WA, Chenevix-Trench $\mathrm{G}$, Arnold J. Analysis of the candidate 8p21 tumour suppressor, BNIP3L, in breast and ovarian cancer. Br J Cancer. 2003;88:270-276.

20. Chaib H, MacDonald JW, Vessella RL, et al. Haploinsufficiency and reduced expression of genes localized to the $8 p$ chromosomal region in human prostate tumors. Genes Chromosomes Cancer. 2003;37:306-313

21. Birnbaum D, Adelaide J, Popovici C, CharafeJauffret E, Mozziconacci MJ, Chaffanet M. Chromosome arm 8p and cancer: a fragile hypothesis. Lancet Oncol. 2003;4:639-642.

22. Rubio-Moscardo F, Climent J, Siebert R, et al. Mantle cell lymphoma genotypes identified with $\mathrm{CGH}$ to BAC microarrays define a leukemic subgroup of disease and predict patient outcome. Blood. 2005; 105:4445-4454

23. Snijders AM, Nowak N, Segraves R, et al. Assembly of microarrays for genome-wide measurement of DNA copy number. Nat Genet. 2001;29: 263-264.

24. Martinez-Climent JA, Alizadeh AA, Segraves R, et al. Transformation of follicular lymphoma to diffuse large cell lymphoma is associated with a heterogeneous set of DNA copy number and gene expression alterations. Blood. 2003;101: 3109-3117.

25. Alizadeh AA, Eisen MB, Davis RE, et al. Distinct types of diffuse large B-cell lymphoma identified by gene expression profiling. Nature. 2000;403: 503-511.

26. De Leeuw RJ, Davies JJ, Rosenwald A, et al. Comprehensive whole genome array CGH profiling of mantle cell lymphoma model genomes. Hum Mol Genet. 2004;13:1827-1837.

27. Fraga MF, Esteller M. DNA methylation: a profile of methods and applications. Biotechniques. 2002;33:632,634,636-649.

28. Ewing B, Green P. Base-calling of automated sequencer traces using phred, II: error probabilities. Genome Res. 1998;8:186-194.

29. Ewing B, Hillier L, Wendl MC, Green P. Base-calling of automated sequencer traces using phred, I accuracy assessment. Genome Res. 1998;8:175185.

30. Bonfield JK, Smith K, Staden R. A new DNA se- quence assembly program. Nucleic Acids Res. 1995;23:4992-4999.

31. Inohara N, del Peso L, Koseki T, Chen S, Nunez G. RICK, a novel protein kinase containing a caspase recruitment domain, interacts with CLARP and regulates CD95-mediated apoptosis. J Biol Chem. 1998;273:12296-12300.

32. Pan G, O'Rourke K, Chinnaiyan AM, et al. The receptor for the cytotoxic ligand TRAIL. Science. 1997;276:111-113.

33. Marsters SA, Sheridan JP, Pitti RM, et al. A nove receptor for Apo2L/TRAIL contains a truncated death domain. Curr Biol. 1997;7:1003-1006.

34. Shin MS, Kim HS, Lee SH, et al. Mutations of tumor necrosis factor-related apoptosis-inducing ligand receptor 1 (TRAIL-R1) and receptor 2 (TRAIL-R2) genes in metastatic breast cancers. Cancer Res. 2001;61:4942-4946.

35. Lee SH, Shin MS, Kim HS, et al. Somatic mutations of TRAIL-receptor 1 and TRAIL-receptor 2 genes in non-Hodgkin's lymphoma. Oncogene. 2001;20:399-403.

36. van Noesel MM, van Bezouw S, Salomons GS, et al. Tumor-specific down-regulation of the tumor necrosis factor-related apoptosis-inducing ligand decoy receptors DcR1 and DcR2 is associated with dense promoter hypermethylation. Cancer Res. 2002;62:2157-2161.

37. Pan G, Ni J, Wei YF, Yu G, Gentz R, Dixit VM. An antagonist decoy receptor and a death domaincontaining receptor for TRAIL. Science. 1997; 277:815-818.

38. Sheridan JP, Marsters SA, Pitti RM, et al. Contro of TRAIL-induced apoptosis by a family of signaling and decoy receptors. Science. 1997;277:818821

39. Zhang XY, Zhang XD, Borrow JM, Nguyen T, Her sey $P$. Translational control of tumor necrosis factor-related apoptosis-inducing ligand death receptor expression in melanoma cells. J Biol Chem. 2004;279:10606-10614.

40. Takimoto R, El-Deiry WS. Wild-type p53 transactivates the KILLER/DR5 gene through an intronic sequence-specific DNA-binding site. Oncogene. 2000;19:1735-1743.

41. Swalwell JI, Vocke CD, Yang Y, et al. Determination of a minimal deletion interval on chromosome band 8p21 in sporadic prostate cancer. Genes Chromosomes Cancer. 2002;33:201-205.
42. Lerebours F, Olschwang S, Thuille B, et al. Fine deletion mapping of chromosome $8 p$ in nonsmall-cell lung carcinoma. Int J Cancer. 1999;81: 854-858.

43. Lerebours F, Olschwang S, Thuille B, et al. Deletion mapping of the tumor suppressor locus involved in colorectal cancer on chromosome band 8p21. Genes Chromosomes Cancer. 1999;25: 147-153.

44. Walczak H, Miller RE, Ariail K, et al. Tumoricidal activity of tumor necrosis factor-related apoptosis-inducing ligand in vivo. Nat Med. 1999;5:157163.

45. Smyth MJ, Cretney E, Takeda K, et al. Tumor necrosis factor-related apoptosis-inducing ligand (TRAIL) contributes to interferon gamma-dependent natural killer cell protection from tumor metastasis. J Exp Med. 2001;193:661-670.

46. Takeda K, Smyth MJ, Cretney E, et al. Critical role for tumor necrosis factor-related apoptosisinducing ligand in immune surveillance against tumor development. J Exp Med. 2002;195:161169.

47. Takeda K, Smyth MJ, Cretney E, et al. Involvement of tumor necrosis factor-related apoptosisinducing ligand in NK cell-mediated and IFNgamma-dependent suppression of subcutaneous tumor growth. Cell Immunol. 2001;214:194-200.

48. Cretney E, Takeda K, Yagita H, Glaccum M, Peschon JJ, Smyth MJ. Increased susceptibility to tumor initiation and metastasis in TNF-related apoptosis-inducing ligand-deficient mice. J Immunol. 2002;168:1356-1361.

49. Diehl GE, Yue HH, Hsieh $\mathrm{K}$, et al. TRAIL-R as a negative regulator of innate immune cell responses. Immunity. 2004;21:877-889.

50. Yue HH, Diehl GE, Winoto A. Loss of TRAIL-R does not affect thymic or intestinal tumor development in p53 and adenomatous polyposis coli mutant mice. Cell Death Differ. 2005;12:94-97.

51. Finnberg N, Gruber JJ, Fei P, et al. DR5 knockout mice are compromised in radiation-induced apoptosis. Mol Cell Biol. 2005;25:2000-2013.

52. Schneider P. Production of recombinant TRAIL and TRAIL receptor: Fc chimeric proteins. Methods Enzymol. 2000;322:325-345.

53. UCSC Genome Bioinformatics. Human (Homo sapiens) genome browser gateway. http:// genome.cse.ucsc.edu/cgi-bin/hgGateway?cladevertebrate\&org-Human\&db-hg17\&hgsid39217703. Accessed August 2005 